THE JECH GALLERY

\title{
Alvan R Feinstein
}

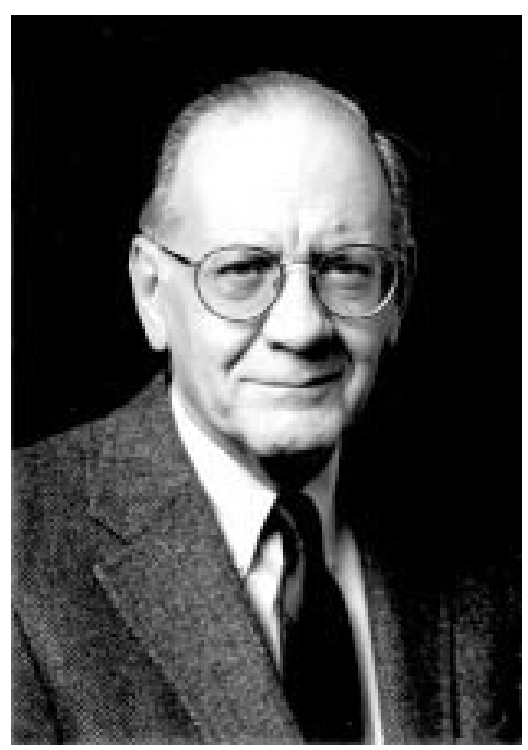

rawing from an inexhaustible source of clinical expertise, clinical research, and intellectual creativity, Alvan R Feinstein (1925-2001) became the founding father of clinical epidemiology. He was professor of Medicine and Epidemiology at Yale University School of Medicine from 1969, Editor of the Journal of Chronic Diseases (1982-1988) and founder and Editor of the Journal of Clinical Epidemiology (1988-2001). He was author of about 800 scientific publications. Most of these were full papers in peer reviewed journals, of which Feinstein was first author in most cases. Feinstein published six authoritative books. Clinical Judgment (1967), Clinical epidemiology: the architecture of clinical research (1985), and Clinimetrics (1987) were breakthroughs in clinical science, and still a breeding ground for innovation. (Photograph reprinted from Journal of Clinical Epidemiology, with permission from Elsevier Science).

J A Knottnerus Netherlands School of Primary Care Research, University of Maastricht, Netherlands

\section{SPEAKER'S CORNER}

\section{Health and development: How are the G7/G8 doing?}

In recent years, the annual G7/G8 summit meetings of the world's most powerful nations have emerged as a major venue for important multilateral commitments that have an impact on health and development issues. Some of these commitments, such as the creation in 2001 of the Global Fund to Fight AIDS, Tuberculosis and Malaria, directly involve health. Others, such as those involving debt relief or trade liberalisation, may affect health indirectly, but in ways that are even more significant.

With support from Canada's International Development Research Centre, we are now developing a report card on how well the G7/G8 nations have lived up to formal and nominal summit commitments that affect human health. The report card will be based on detailed textual analysis of documents from the last three summits, crucially including the New African Initiative (now re-christened the New Partnership for Africa's Development) as well as the extensive research literature on health and development. Our research will be informed by the work of the University of Toronto G8 Research Group and Information Centre (accessible at http://www.g7.utoronto.ca). By the time this piece appears we will have posted an inventory of health related and development related summit commitments on the Saskatchewan Population Health and Evaluation Research Unit web site (http://www.spheru.ca). We will also evaluate the normative conception of the relations among economic policy, development trajectories and the social determinants of health that underlies the policies of the G7/G8. As Canada is hosting this year's summit in Kananaskis, Alberta, the report card will be provided to Canadian Summit organisers and delegations in advance of the meeting.

Ours is, to put it mildly, an ambitious research project given the short time frame. We hope, however, that it will be the first step in a larger scale, longer term international collaboration. Canada has taken promising steps in this direction, by way of an agreement among four federal agencies to establish a Global Health Research Initiative. Dr Allan Ronald, a spokesman for Canada's Global Health Research Coalition, has called the agreement "an important first step for Canada's role in improving the 10-90 gap" - the set of priorities that sees $90 \%$ of the world's $\$ 73.5$ billion health research and development budget (as of 1998) spent on the health problems of the richest $10 \%$ of the world's population.

We welcome communications from researchers, clinicians and non-governmental organisations concerned with health and development about information resources that can be used to develop indicators of progress toward health and development goals that are as clear and unambiguous as possible; critical, independent published sources that can be used to evaluate the performance of national governments; and using critical, independent published sources as well as governments' own official statements; and conceptual frameworks or pathways models that can be used to analyse and explain the complex relations among public policy, international political economy, and human health.

R Labonte

Saskatchewan Population Health and Evaluation Research Unit, Universities of Regina and Saskatchewan, Canada

D Sanders

School of Public Health, University of the Western Cape, South Africa

T Schrecker

Centre for Medicine, Ethics and Law, McGill University, Canada

Correspondence to: Dr R Labonte; ronald.labonte@usask.ca 